\title{
TANTANGAN EKONOMI DIGITAL UNTUK PARIWISATA INDONESIA MENGGUNAKAN METODE FORECASTING
}

\author{
Ismail $^{1}$, Taufik Hidayat ${ }^{2}$ \\ 1,2Department of Computer Engineering, Universitas Wiralodra, Indonesia \\ arsip.ismaildahsyat@gmail.com, thidayat.ft@unwir.ac.id
}

\begin{abstract}
ABSTRAK
Perkembangan ekonomi digital di Indonesia telah mengalami kemajuan yang sangat pesat salah satunya di bidang pariwisata. Kemajuan ekonomi digital dibidang pariwisata dapat menarik wisata nusantara (winus) maupun manca negara berkunjung ketempat wisata Indonesia. Dampak dari kemajuan ekonomi digital mengangkat banyak usaha kecil dan menengah untuk memasuki bisnis dunia. Pertumbuhan ekonomi Indonesia yang cukup tinggi layanan kepariwisataan Indonesia masih sedikit layanan digital yang dikembangkan. Dari analisa perkembangan layanan digital dibidang pariwisata menggunakan method forecasting dari data yang diambil dapat memprediksi 10 tahun ditahun 2028 pengeluaran 465,1 Triliun rupiah dan perjalanan 425,75 juta kali perjalanan kalau dibandingkan dari tahun 2018 pada pengeluaran 291,09 Trilium rupiah dan perjalanan hanya 303,4 juta kali perjalanan, dari analisa yang didapat memiliki peluang bagi teknopreneur untuk membuat starup dibidang pariwisata yang menjembatani atara pariwiswata dan wisatawan nusantara tentu menguntungkan bagi pertumbuhan ekonomi Indonesia dengan menggunakan digital ekonomi di era industri ekonomi digital ini.
\end{abstract}

Kata Kunci: industri ekonomi digital, pariwisata, wisatawan nusantara, forecasting

\section{ABSTRACT}

The development of the digital economy in Indonesia has increased very rapidly, one of which is in the field of tourism. The progress of the digital economy is attracting domestic or foreign tourism to Indonesia. The impact of the progress of the digital economy is increasing small and medium-sized businesses to start world businesses. Indonesia's economic services are quite high Indonesian tourism is still little digital services developed. From the analysis of the development of digital services using the forecasting method from data taken can predict 10 years in 2028 issued 465.1 Trillion rupiah and trips 425.75 million trips compared to 2018 at 291.09 Trillion rupiah movements and trips only 303.4 million trips, from the analysis obtained from the opportunity for technopreneur to create a star that bridges between tourism and archipelago tourists, of course, beneficial for Indonesia's economic growth by using the digital economy in the era of the digital economy industry.

Keywords: digital economy industry, tourism, domestic tourists, forecasting

\section{PENDAHULUAN}

Ekonomi digital lahir dan berkembang seiring menglobalnya pengguna teknologi informasi dan komuniaksi di dunia. Ekonomi digital merupakan 'sharing economy' yang sangat mengangkat banyak usaha kecil dan menengah untuk memasuki bisnis dunia [1], sedangkan pada perkembangan pariwisata Indonesia dari tahun ke tahun tercatat terus tumbuh bahkan daya saing sektor pariwisata Indonesia terus mengalami peningkatan. Pesatnya perkembangan kondisi pariwisata nasional disinyalir sebagai dampak dari pertumbuhan ekonomi Indonesia yang cukup tinggi yang disertai peningkatan daya beli masyarakat serta didukung dengan kondisi keamanan yang cukup 
kondusif, maka hal ini akan mendorong meingkatnya jumlah kunjungan wisatawan, khususnya kunjungan penduduk Indonesia untuk melakukan perjalanan wisata di wilayah territorial Indonesia atau disebut kunjangan wisatawan nusantara (winus) [2], hanya saja masih berjalan secara konvensional belum ada atau masih sangat sedikit yang dikembangkan dengan layanan digital baik digunakan untuk promosi keindahan dan fasilitasnya, resevasi; pemesanan secara elektronik atau secara garis besarnya belum menggunakan sistem ekonomi digitalnya, maka disini muncul peluang dan tantangan kepada para teknopreneur untuk dapat membuat atau mengembangkan sistem ekonomi digital bisa saja sebuah aplikasi yang berbasis mobile atau internet yang dengan aplikasi ini harus dapat menjawab kebutuhan pariwisata dan wisatawannya, diantara pertanyaan atau tantangan itu adalah sebagai berikut :

1. Pariwisata yang tersebar di nusantara harus mudah ditemukan, dengan keunggulan pariwisatanya dan fasilitas-failitasnya, baik berdasarkan daerah atau kepulauannya maupun berdasarkan biayanya.

2. Wisatawan bisa mencari pariwisata menyesuaikan lokasi, transportasinya dan biayanya.

3. Mampu memberikan rekomendasi kepada pihak pariwisata untuk berpromosi kepada wisatawan di daerah / kepulan terntentu, begitupun sebaliknya mampu memberikan rekomendasi kepada wisatawan untuk memilih pariwisata di daerah/kepulauan tertentu dengan disesuiakan keunggulan, fasilitas dan biayanya serta transportasi dan penginapannya dan makananya.

Maka perlu mempelajari studi sebelumnya guna mendapatkan irisan apakah sudah ada studi sebelumnya yang berkaitan dengan penerapan digital ekonomi, berikut ini data tabel 1 menunjukkan studi sebelumnya.

Tabel 1. Studi sebelumnya Digital Ekonomi

\begin{tabular}{|c|c|c|}
\hline Jurnal & Tahun & HasilRiset \\
\hline [3] & 2018 & \begin{tabular}{lr} 
Semakin & \multicolumn{2}{c}{ pentingnya } \\
mengukur PDB di \\
ekonomi digital karena \\
meningkatnya \\
kekhawatiran \\
keterbatasan
\end{tabular} \\
\hline
\end{tabular}

\begin{tabular}{|c|c|c|}
\hline & & $\begin{array}{l}\text { PDB, ini solusi praktis } \\
\text { dan baru. }\end{array}$ \\
\hline [4] & 2019 & $\begin{array}{lr}\text { Membuka } & \text { jalan } \\
\text { cara untuk membuat } \\
\text { informasi yang Seragam } \\
\text { ke konsorsium sistem } \\
\text { organisasi r yang } \\
\text { melaksanakan } \\
\text { program pemerintah dan } \\
\text { proyek bisnis. Informasi } \\
\text { seragam } \\
\text { berdasarkan digital dibuat }\end{array}$ \\
\hline [5] & 2019 & $\begin{array}{lr}\text { Lebih dari } & 80 \% \text { dari } \\
\text { publikasi menganggap } \\
\text { ekonomi digital } & \text { sebagai } \\
\text { hubungan } & \text { ekonomi } \\
\text { digital } & \text { yang } \\
\text { memungkinkan } & \\
\text { peningkatan } & \text { ekonomi } \\
\text { yang penting } & \text { sebagai } \\
\text { indikator kinerja } & \\
\end{array}$ \\
\hline [6] & 2019 & $\begin{array}{lr}\text { Perlunya } & \\
\text { perubahan } & \text { dalam } \\
\text { pelatihan spesialis TI } \\
\text { dalam } & \text { pandangan } \\
\text { pengembangan } & \text { dan } \\
\text { dampak ekonomi } & \text { digital } \\
\text { pada } & \text { proses } \\
\text { pembelajaran. }\end{array}$ \\
\hline [7] & 2018 & $\begin{array}{l}\text { Dorongan GCC untuk } \\
\text { terlibat dalam kota-kota } \\
\text { digital dan cerdas } \\
\text { tidak mengherankan. } \\
\text { Sekarang ada dunia maya } \\
\text { yang lebih luas } \\
\text { industri, ekonomi virtual } \\
\text { yang beroperasi }\end{array}$ \\
\hline [8] & 2019 & $\begin{array}{l}\text { Analisis tren dan } \\
\text { perkiraan perubahan di } \\
\text { keterampilan dan } \\
\text { kompetensi digital dan } \\
\text { non-digital yang diminta } \\
\text { olehpengusaha dan } \\
\text { menentukan kesuksesan } \\
\text { profesional masa depan } \\
\text { insinyur dalam ekonomi } \\
\text { digital yang disajikan. }\end{array}$ \\
\hline [9] & 2017 & $\begin{array}{lr}\text { Relevansi pembentukan } \\
\text { ekonomi digital nasional } \\
\text { dikonfirmasi } & \text { oleh } \\
\text { kehadiran tren } & \text { global } \\
\text { digitalisasi } & \text { masyarakat } \\
\text { internasional } & \text { dan } \\
\text { kebutuhan } & \text { untuk }\end{array}$ \\
\hline
\end{tabular}




\begin{tabular}{|c|c|c|}
\hline & & $\begin{array}{l}\text { melestarikan } \\
\text { kedaulatan digital. }\end{array}$ \\
\hline [10] & 2019 & $\begin{array}{l}\text { Fitur utama ekonomi } \\
\text { digitalpenilaian } \\
\text { pengembangan sebagai } \\
\text { alat untuk mengelola } \\
\text { digital } \\
\text { proses transformasi di } \\
\text { tingkat nasional, regional } \\
\text { dan sektoral } \\
\text { level disajikan. }\end{array}$ \\
\hline [11] & 2018 & \begin{tabular}{lr}
\multicolumn{2}{l}{ Konstruksi } \\
dari jejaring & sosial \\
menunjukkan & hasil \\
spesifik yang disorot & komponen ideologis yang \\
menyertai istilah & "digital \\
ekonomi "- penanda \\
emosional, r yang \\
diprogram secara sosial.
\end{tabular} \\
\hline [12] & 2017 & $\begin{array}{l}\text { Perkembangan ekonomi } \\
\text { digital tidak bisa } \\
\text { dikelola tanpa } \\
\text { mempertimbangkan } \\
\text { kepentingan semua } \\
\text { pemangku kepentingan } \\
\text { dan (organisasi, tenaga } \\
\text { kerja, dan keuangan } \\
\text { negara dan bisnis) }\end{array}$ \\
\hline [13] & 2018 & $\begin{array}{l}\text { Menggambarkan } \\
\text { ekonomi digital } \\
\text { sebagai lingkungan } \\
\text { komunikasi non- } \\
\text { transaksionalagen } \\
\text { otonom membawa } \\
\text { banyak konsekuensi, dari } \\
\text { "a" revisi lengkap model- } \\
\text { model risiko, hingga } \\
\text { munculnya yang baru }\end{array}$ \\
\hline
\end{tabular}

dan ternyata dari tabel diatas didapatkan penerapan digital eknomi di berbagai bidang, akan tetapi masih sedikit bahkan boleh dikatan belum ada penerapan di pariwisata, maka ini semakin kuat untuk menjawab tantangan untuk mewujudkan digital ekonomi di pariwisata Indonesia.

\section{PENELITIAN TERKAIT}

\subsection{Industri Ekonomi Digital}

Berbicara ekonomi digital yang biasanya merupakan penerapan cloud computing [14] lebih popular dengan sebutan sistem digitalisasi, kemudian diketahui data pertumbuhan ekonomi digital Indonesia berdasarkan study ekonomi digital Indonesia pertubuhannya sangat pesat.

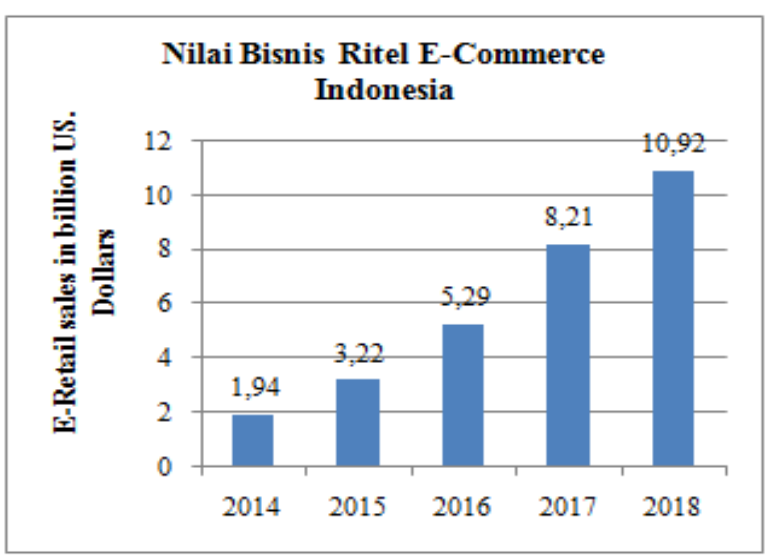

Gambar 1. E-Commerce Indonesia [1]

Dari grafik diatas kita bisa melihat kenaikan nilai bisnis ritel E-Commerce Indonesia dari tahun ke tahun rata-rata US\$ 2,245 (billion US. Dollars), Sedangkan Prospek Bisnis ECommerce Indonesia begitu prospektif dilihat dari jumlah pengguna internet Indonesia

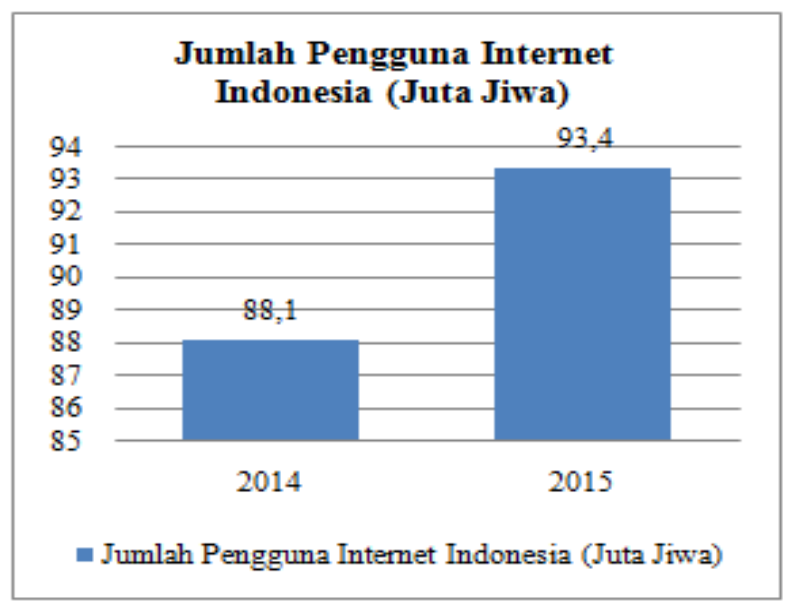

Gambar 2. Pengguna Internet Indonesia [1]

Kemudaian dari tabel dibawah ini terlihat produk E-commerce yang paling sering di cari sebagai berikut :

Tabel 1. Produk E-commerce sering cari [1]

\begin{tabular}{lc}
\hline \multicolumn{1}{c}{ Pencarian } & Pesentase (\%) \\
\hline Penggunaan Internet & 93,4 \\
\hline Pakaian & 67,10 \\
\hline
\end{tabular}




\begin{tabular}{lc}
\hline Sepatu & 20,20 \\
\hline Tas & 20 \\
\hline Jam & 7,6 \\
\hline Tiket Pesawat & 5,10 \\
\hline Hand Phone & 2,80 \\
\hline Kosmetik & 2,30 \\
\hline Buku & 1,80
\end{tabular}

Ditampilkan dalam grafik sebagai berikut:

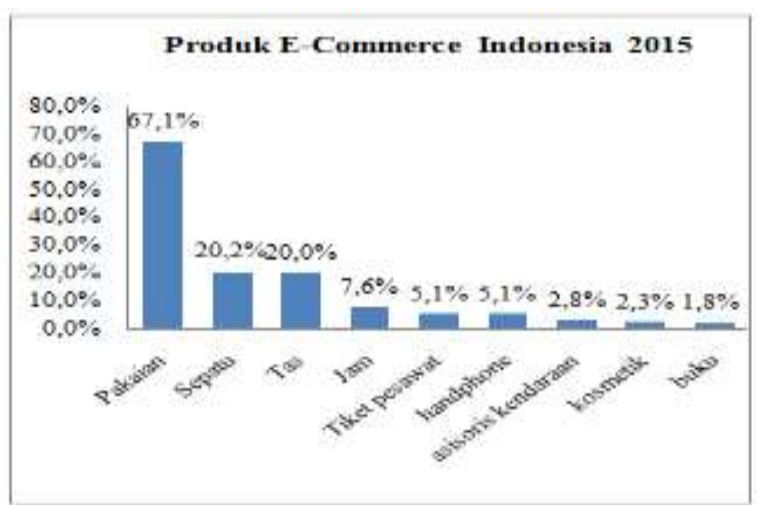

Gambar 3. Produk E-Commerce Indonesia [1]

Terlihat dari gambar diatas prosentase pakaian tertinggi kemudain sepatu dan tas, ditengah-tengah ada tiket pesawat dan handphone hingga yang paling rendah adalah buku.

\subsection{Wisatawan Nusantara}

Wisatawan Nusantara tercatat sangat pesat dilihat dari data BPS (BadanPusatStatistik).

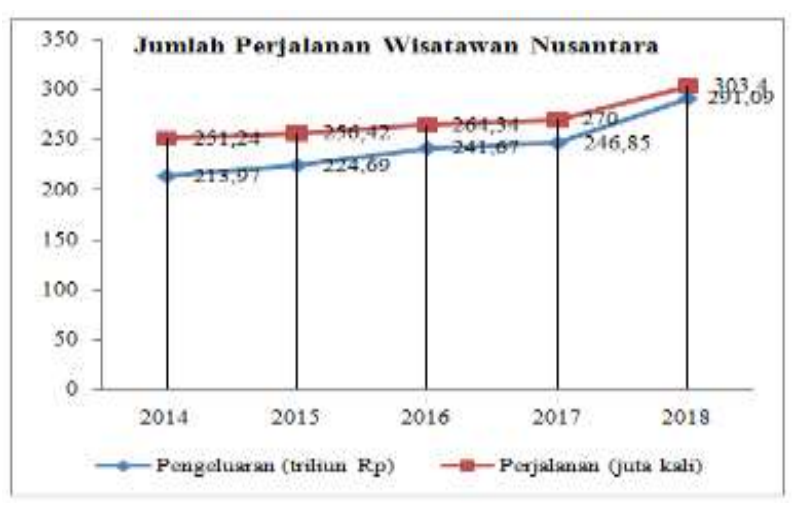

Gambar 4. Perjalanan Wisatawan [2]
Dari gambar diatas kita bisa melihat bahwa kenaikan perjalanan wisatawan nusantara dari tahun 2014 - 2018 rata-rata 13,04 juta kali perjalanan, dan rata-rata pengeluarannya Rp. 19 , 28 triliun rupiah, ini angka yang sangat fantastis dan mengundang tantangan bagi kaum teknopreneur, tantangannya adalah "apa yang harus dibuat dengan potensi wisatawan nusantara yang begitu besar perjalanan dan pengeluarannya?"

Kemudian dilihat dari segi transportasinya seperti terlihat pada gambar dibawah ini:

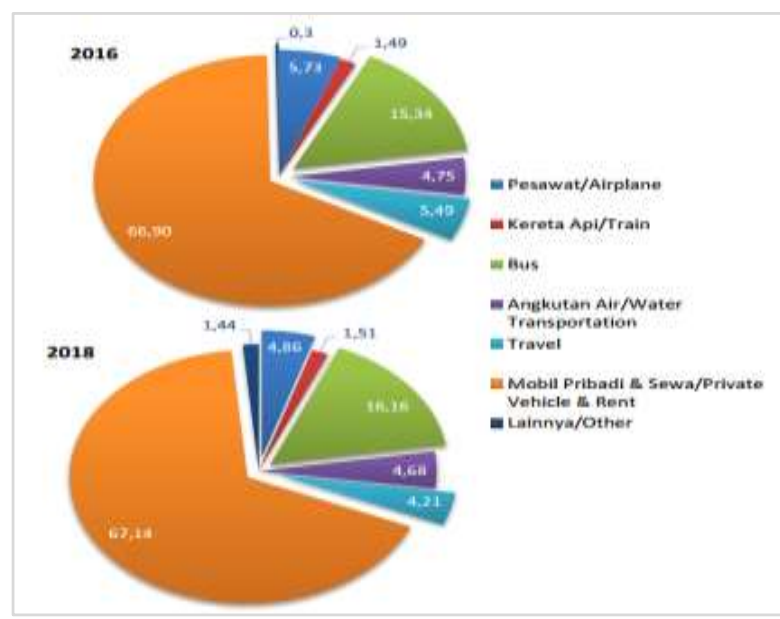

Gambar 5. Perjalanan dengan angkutan [2]

Terlihat dari gambar grafik diatas mode angkutan yang paling tinggi digunakan adalah mobil pribadi, ini menunjukkan peluang dan tantangan untuk seorang teknoprenuer harus bisa menjawab ini, artinya ketika membuat aplikasi digital economy nya harus mampu memberikan pilihan moda angkutan yang terjangkau dan paling sering digunakan.

Kemudian dilihat dari sebaran kelompok umur penduduk yang melakukan perjalanan wisatawan nusantara

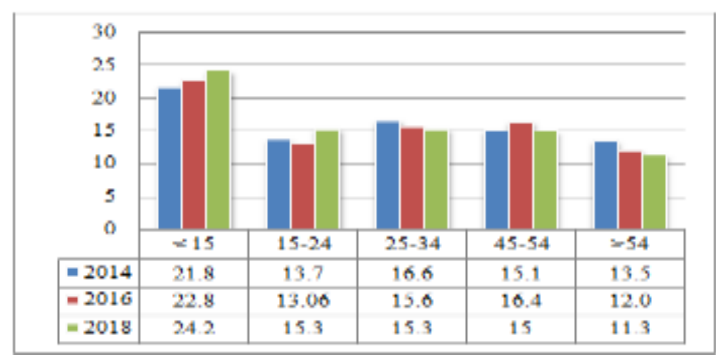

Gambar 6. Penduduk Indonesia melakukan perjalanan [2] 
Dari gambar grafik diatas terlihat data tertinggi pada tahun 2018 yang melakukan perjalanan sebagai wisatawan nusantara adalah kelompok umur dibawah 15 tahun, ini adalah peluang besar dan tantangan sekaligus agar nantinya para teknopreneur bisa membuat aplikasi yang mengakomodir berdasarkan usia wisatawan.

Selain tingginya perjalanan dan pengeluaran wisatawan nusantara juga dipengaruhi oleh kemampuan daya konsumsi penduduk Indonesia [15], berikut ini data-data pengeluaran dan konsumsi penduduk Indonesia yang didapatkan dari Badan Pusat Statistik.

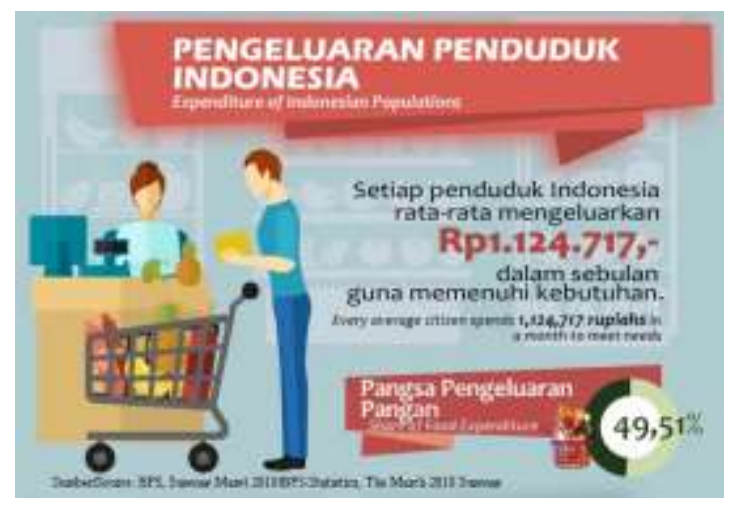

Gambar 7. Pengeluaran Penduduk Indonesia [15]

Dari gambar diatas disebutkan setiap penduduk Indonesia rata-rata mengeluarkan Rp. 1.124.717,- dalam sebulan untuk memenuhi kebutuhan, dengan pangsa pengeluaran pangan $49,51 \%$, kemudian dilihat dari rata-rata perkapitanya seperti terlihat pada gambar dibawah ini.

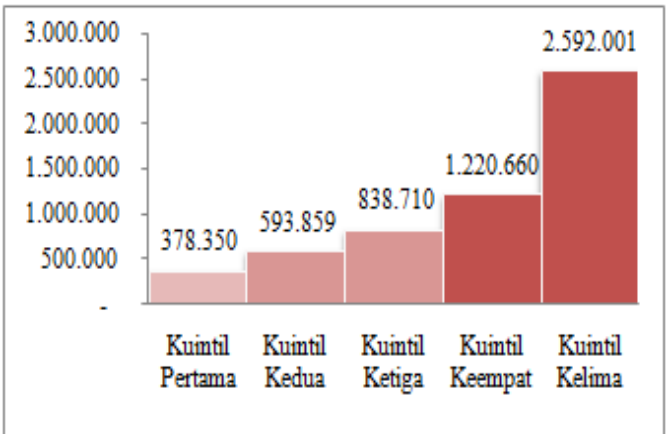

Gambar 8. Data pengeluran masyarkat Indonesia [15]
Dari data diatas memperlihatkan erat kaitannya wisatawan nusantara ketika melakukan perjalanan wisata secara otomatis melakukan pengeluaran untuk konsumsi, maka ini juga peluang sekaligus tantangan agar para teknopreneur bisa menjawab dengan aplikasi atau startup yang bisa menyediakan konsumsi sesuai kemampuan daya konsumsi penduduk Indonesia.

\section{METODE PENELITIAN}

\subsection{Forecasting Method}

Dengan menggunakan metode forecasting regresi linier [16], [17], [18], dalam metode ini, ada data yang nantinya digunakan sebagai bahan untuk membentuk persamaan $\mathrm{Y}=\mathrm{a}+\mathrm{b} \times$ [17], berikut ini penjelasannya :

- Y: variabel berfluktuasi yang merupakan nilai pengamatan selama periode tertentu maksudnya adalah variable yang akan di olah dengan forecasting dalam kasus ini sebagai variable Y nya adalah "pengeluaran (triliun rupiah)" dan "perjalanan (juta kali)".

- a: koefisien arah dalam kasus ini adalah total pengeluran dan perjalanan di bagi banyaknya periode.

- $\mathrm{x}$ : periode tertentu yang dihitung melalui deviasi tertentu.

- b: koefisien arah kecenderungan.

Rumus ditulis untuk menghitung konstanta a dan $\mathrm{b}$

$$
b=\frac{n \sum x_{i} y_{i}}{n \sum x_{i}^{2}-\left(\sum x_{i}\right)^{2}}, a=\bar{y}-b \bar{x}
$$

Sedangkan untuk menghitung forecasting sebagai berikut:

$$
Y^{\prime}=a+b x
$$

Nilai $\mathrm{x}$ dan $\mathrm{y}$ diambil dari data-data sebelumnya yang dijadikan sebagai sample data.

\subsection{Data Source}

Sumber data yang digunakan terdiri dari dua variabel yakni data pengeluaran dan data perjalanan selama tahun $2002-2018$, dengan Rumus $Y^{\prime}=a+b x$, pertama-tama mengolah data pengeluaran dalam satuan Triliun Rupiah sebagai Y. 
Tabel 3. Perjalanan dan Pengeluaran Wisatawan Nusantara [2]

\begin{tabular}{ccc}
\hline Tahun & $\begin{array}{c}\text { Pengeluaran } \\
\text { (triliunRp) }\end{array}$ & $\begin{array}{c}\text { Perjalanan } \\
\text { (juta kali) }\end{array}$ \\
\hline 2002 & 68,82 & 200,59 \\
\hline 2003 & 70,87 & 207,12 \\
\hline 2004 & 71,70 & 202,76 \\
\hline 2005 & 74,72 & 198,36 \\
\hline 2006 & 88,21 & 204,55 \\
\hline 2007 & 108,96 & 222,39 \\
\hline 2008 & 123,17 & 225,04 \\
\hline 2009 & 137,91 & 229,73 \\
\hline 2010 & 150,41 & 234,38 \\
\hline 2011 & 160,89 & 236,75 \\
\hline 2012 & 172,85 & 245,29 \\
\hline 2013 & 177,84 & 250,04 \\
\hline 2014 & 213,97 & 251,24 \\
\hline 2015 & 224,69 & 256,42 \\
\hline 2016 & 241,67 & 264,34 \\
\hline 2017 & 246,85 & 270 \\
\hline 2018 & 291,09 & 303,4 \\
\hline
\end{tabular}

Dari tabel diatas dicari baris tengahtengahnya untuk menentukan nilai $\mathrm{x}$, maka di dapatkan pada baris ke 9 atau baris tahun 2010 kemudian tentukan sebagai nilai 1 , kemudian ke bawah di tambahkan dengan 2, sedangkan nilai keatas ditambahkan -2, seterusnya dengan menggunakan rumus forecasting regresi liner diatas maka akan diperoleh hasil prediski 10 tahun yang akan datang.

\subsection{Studi Kasus}

Dari data souce perjalanan dan pengeluaran yang ada bisa dilakukan pengujian data sampel yang dilakukan.

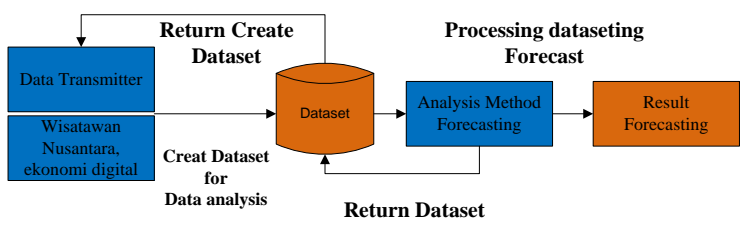

Gambar 9. Study Kasus Ekonomi Digital [10]

Terlihat dari gambar flowchart diatas, data sumber (data perjalanan dan pengeluaran) wisatawa nusantara dibuat sesuai format kolom dan baris dalam tabel yang menjadi dataset atau data yang sudah di atur, apabila data sumber tidak sesuai formatnya maka dikembalikan untuk atur kembali formatnya menjadi dataset, selanjutnya dataset yang sudah siap maka di proses analisanya menggunakan metode forecasting, hasil proses sementaranya dikembalikan menjadi dataset kemudian diproses kembali sampai hasil akhirnya diketahui sesuai batas perkiraan untuk prediksi berapa tahun ke depan, setelah selesai maka hasilnya akan di tampilkan.

\section{HASIL DAN PEMBAHASAN}

Berdasarkan perhitungan yang sudah digambarkan pada flowchart diatas dengan rumus forecaseting regresi liner maka didapatkan hasil sebagai berikut terlihat dari tabel 4.

Tabel 4. Hasil prediksi 10 Tahun

\begin{tabular}{ccc}
\hline Tahun & $\begin{array}{c}\text { Pengeluaran } \\
\text { (triliunRp) }\end{array}$ & $\begin{array}{c}\text { Perjalanan } \\
\text { (juta kali) }\end{array}$ \\
\hline 2019 & 313,95 & 333,16 \\
\hline 2020 & 330,74 & 343,45 \\
\hline 2021 & 347,54 & 353,74 \\
\hline 2022 & 364,34 & 364,02 \\
\hline 2023 & 381,13 & 374,31 \\
\hline 2024 & 397,93 & 384,60 \\
\hline 2025 & 414,72 & 394,89 \\
\hline 2026 & 431,52 & 405,17 \\
\hline 2027 & 448,31 & 415,46 \\
\hline 2028 & 465,11 & 425,75 \\
\hline
\end{tabular}

Dari haasil analisa forecasting pada tabel 4 dapat digambar kedalam grafik.

\section{Hasil Prediksi Perjalanan dan Pengeluaran}

600,00

400,00

200,00
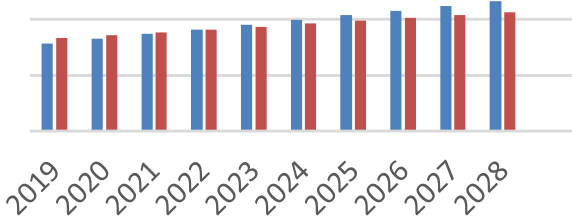

- Perjalanan Triilun (Rp) $\square$ Pengeluaran (Juta Kali)

Gambar 10. Hasil analisa forecasting 20192028 
Dari tabel dan grafik diatas memperlihatkan pengeluaran yang sangat besar di tahun 2028 di angka 465,11Triliun Rupiah, dengan perjalanan terbanyak 425,75 juta kali, ini menunjukkan sangat besarnya peluang dan tantangan di dunia industri digital ekonomi, artinya jika dengan dibuatnya sebuah aplikasi untuk menjawab tantangan ini misalkan hanya bisa 'menangkap' peluang $10 \%$ dari pengeluaran $(465,11 \mathrm{~T})$ nya saja maka akan didapatkan 46,5 Triliun Rupiah, sungguh menjanjikan.

\section{KESIMPULAN}

Dari hasil analisa perhitungan forecasting dengan maka didapatkan perkiraan 10 tahun yang akan datang untuk perjalanan dan pengeluaran wisatawan nusantara yang memiliki peluang begitu besar untuk dikembangkan dengan sebuah aplikasi atau startup yang termasuk digital ekonominya di era industri ekonomi digital ini, dan harus mampu mengambil peluang dan sekaligus menjawab tantangan-tantangan pariwisata nusantaran ditemukan dengan mudah, mencari lokasinya serta biayanya. Melahirkan startup yang berbasis teknologi. Saran untuk penelitian selanjutnya mengkombinasian forecasting dengan method markov chain agar meghasilkan riset yang lebih detail peluangnya.

\section{UCAPAN TERIMAKASIH}

Penulis ingin mengucapakan banyak terima kasih kepada Department of Computer Engineering, Universitas Wiralodra yang telah memberikan kesempatan kepada penulis untuk riset.

\section{DAFTAR PUSTAKA}

[1] Kominfo, "Study Ekonomi Digital di Indonesia Sebagai Pendorong Utama Pembentukan Industri Digital Masa Depan. 2018.

[2] W. Nusantara, Statistik wisatawan nusantara. 2018.
[3] C. Watanabe, K. Naveed, Y. Tou, and P. Neittaanmäki, "Measuring GDP in the digital economy: Increasing dependence on uncaptured GDP," Technol. Forecast. Soc. Change, vol. 137, no. October 2017, pp. 226-240.

[4] A. A. Zatsarinnyy and A. P. Shabanov, "Model of a Prospective Digital Platform to Consolidate the Resources of Economic Activity in the Digital Economy," Procedia Comput. Sci., vol. 150, pp. 552-557, 2019.

[5] D. Vorobieva, I. Kefeli, M. Kolbanev, and A. Shamin, "Architecture of Digital Economy," in 2018 10th International Congress on Ultra Modern Telecommunications and Control Systems and Workshops (ICUMT), 2018, vol. 2018-Novem, pp. 1-7.

[6] B. Alonzo, P. Tankov, P. Drobinski, and R. Plougonven, "Probabilistic wind forecasting up to three months ahead using ensemble predictions for geopotential height," Int. J. Forecast., no. xxxx, 2019.

[7] M. Balnaves, "Digital Economy Planning in Kuwait," 2018 11th C. Int. Conf. Prospect. Challenges Towar. Dev. a Digit. Econ. within EU, pp. 32-37, 2018.

[8] E. E. Kotova, "Communication Technologies in the Training of IT Specialists in the Digital Economy," in 2019 Communication Strategies in Digital Society Workshop (ComSDS), 2019, pp. 30-33.

[9] S. A. Petrenko, K. A. Makoveichuk, P. V. Chetyrbok, and A. S. Petrenko, "About readiness for digital economy," Proc. 2017 IEEE 2nd Int. Conf. Control Tech. Syst. CTS 2017, pp. 96-99, 2017.

[10] T. V. Ershova, Y. E. Hohlov, and S. B. Shaposhnik, "Methodology for Digital Economy Development Assessment as a Tool for Managing the Digital Transformation Processes," in 2018 Eleventh International Conference "Management of large-scale system development" (MLSD, 2018, vol. 2, no. 3 , pp. 1-3. 
[11] O. Mikhailova, G. Gradoselskaya, and A. Kharlamov, "Social Network Analysis of the Functional Meaning of the Term 'Digital Economy' *," Proc. 2018 11th Int. Conf. \&quot;Management LargeScale Syst. Dev. MLSD 2018, pp. 1-3, 2018.

[12] V. V. Varshavskaya, M. V. Tikhonova, A. G. Komarov, and P. I. Tishkov, "The issues of engineering economic education for digital economy," in 2017 IEEE VI Forum Strategic Partnership of Universities and Enterprises of Hi-Tech Branches (Science. Education. Innovations) (SPUE), 2017, vol. 2018Janua, pp. 211-214.

[13] D. E. Kozhevnikov and A. S. Korolev, "Digital Trust As a Basis for the Digital Transformation of the Enterprise and Economy," Proc. 2018 11th Int. Conf. \&quot;Management Large-Scale Syst. Dev. MLSD 2018, pp. 1-3, 2018.

[14] T. Hidayat, "Encryption Security Sharing Data Cloud Computing by Using AES Algorithm : A Systematic Review," vol. 2, no. 2, 2019.

[15] BPS, Ringkasan Eksekutif Pengeluaran dan Konsumsi Penduduk Indonesia. 2018.

[16] Y. Wang, Q. Chen, M. Sun, C. Kang, and Q. Xia, "An Ensemble Forecasting Method for the Aggregated Load With Subprofiles," IEEE Trans. Smart Grid, vol. 9, no. 4, pp. 3906-3908, Jul. 2018.

[17] S. Kumar, S. Mishra, and S. Gupta, "Short term load forecasting using ANN and multiple linear regression," Proc. 2016 2nd Int. Conf. Comput. Intell. Commun. Technol. CICT 2016, pp. 184186, 2016.

[18] S. Swain, P. Patel, and S. Nandi, "A multiple linear regression model for precipitation forecasting over Cuttack district, Odisha, India," 2017 2nd Int. Conf. Converg. Technol. I2CT 2017, vol. 2017-Janua, pp. 355-357, 2017.

[19] L. Sanny and H. Sarjono, "Peramalan Jumlah Siswa / I Sekolah Menengah Atas Swasta Menggunakan Enam Metode Forecasting," Forum Ilm., vol. 10, no. 2, pp. 198-208, 2013. 